\title{
FDG-PET abnormalities leading to the diagnosis of an unusual case of probable neurosarcoidosis
}

Yujie Wang, MD, James Andrews, MD, Paula Jenkins Colon, MD, and Annette Wundes, MD

Neurol Neuroimmunol Neuroinflamm 2018;5:e506. doi:10.1212/NXI.0000000000000506

\author{
Correspondence \\ Dr. Wang \\ yujie.wang87@gmail.com
}

Sarcoidosis is a systemic illness of unknown etiology, characterized histologically by the formation of noncaseating granulomata in the affected tissue. The most common sites of involvement include the pulmonary system; however, neurologic involvement may be seen as well, though typically presenting with systemic findings. ${ }^{1}$ Diagnosing sarcoidosis is challenging due to the lack of reliable serum or imaging markers and hence typically relies on tissue diagnosis. ${ }^{1}$ Although fluorodeoxyglucose positron emission tomography (FDG-PET) has been used in the diagnosis of sarcoidosis, its role is not well established. ${ }^{2-4}$ FDG-PET is an imaging technique wherein FDG, a glucose analogue, is introduced into the body, where it is metabolized with varied rates by different cells. ${ }^{2-4}$ Certain conditions, such as malignancy or inflammatory disease, demonstrate increased metabolism and therefore uptake of FDG, which is visualized by PET scan. We report a case of probable neurosarcoidosis presenting with an unusual pattern of FDG uptake without concomitant brain MRI findings.

\section{Case report}

A 48-year-old woman with generalized anxiety disorder presented with 1 month of recurrent fevers of unclear etiology, pancytopenia, and progressive neurologic symptoms including dysarthria, vertigo, diplopia, and severe gait ataxia with inability to walk. Her neurologic symptoms had a waxing and waning course, worse during febrile episodes. Her examination was notable for dysconjugate gaze with left eye exotropia, multidirectional nystagmus, and gait instability. She underwent multiple brain MRI scans with gadolinium contrast (sequences: sagittal and axial T1 precontrast, axial $\mathrm{T} 1$ postcontrast, sagittal and coronal $\mathrm{T} 1$ fat sat postcontrast, axial T2 FLAIR, sagittal and axial T2, diffusion-weighted imaging, and apparent diffusion coefficient), which demonstrated mild generalized volume loss and mega cisterna magna, but no other abnormal findings (figure). MRI of her cervical spine was unremarkable. Extensive infectious workup was unrevealing (negative bacterial culture, bacterial PCR, mycobacterial PCR, fungal PCR, and viral PCR [varicella zoster virus, herpes simplex virus, enterovirus], toxoplasma immunoglobulin $\mathrm{M} /$ immunoglobulin G, Bartonella Ab, Borrelia species Ab, Treponema pallidum, Lyme disease, QuantiFERON Gold, and HIV). Laboratory studies showed positive antinuclear antibody, with homogenous and speckled pattern at 1:320, indeterminate antichromatin and negative antidsDNA, complement levels, and antiphospholipid antibody panel. A paraneoplastic panel was negative. CSF analysis showed 3 red blood cells, 11 white blood cells (92\% lymphocytes), protein $45(\mathrm{mg} / \mathrm{dL})$, and glucose $97(\mathrm{mg} / \mathrm{dL})$. Serum and CSF angiotensin-converting enzyme levels were within normal limits. CT of the chest, abdomen, and pelvis was notable for mild bilateral axillary lymphadenopathy, splenomegaly, and a left ovarian cystic lesion. Pelvic ultrasound showed a benign-appearing left ovarian cyst, and her mammogram was negative. A bone marrow biopsy demonstrated no evidence of malignancy and was normal. Given the concern for malignancy, whole-body FDG-PET CT scan was performed (2 days after the most recent brain MRI), which showed diffusely increased FDG uptake in the bilateral cerebellar hemispheres, splenomegaly, and FDG avid subpectoral and mesenteric lymph nodes not detected on previous CT (figure). She

From the Department of Neurology (Y.W., A.W.), University of Washington; Division of Rheumatology (J.A.), Department of Internal Medicine, University of Washington; and Department of Pathology (P.J.C.), University of Washington, Seattle.

Funding information and disclosures are provided at the end of the article. Full disclosure form information provided by the authors is available with the full text of this article at Neurology.org/NN.

The Article Processing Charge was funded by the authors.

This is an open access article distributed under the terms of the Creative Commons Attribution-NonCommercial-NoDerivatives License 4.0 (CC BY-NC-ND), which permits downloading and sharing the work provided it is properly cited. The work cannot be changed in any way or used commercially without permission from the journal. 


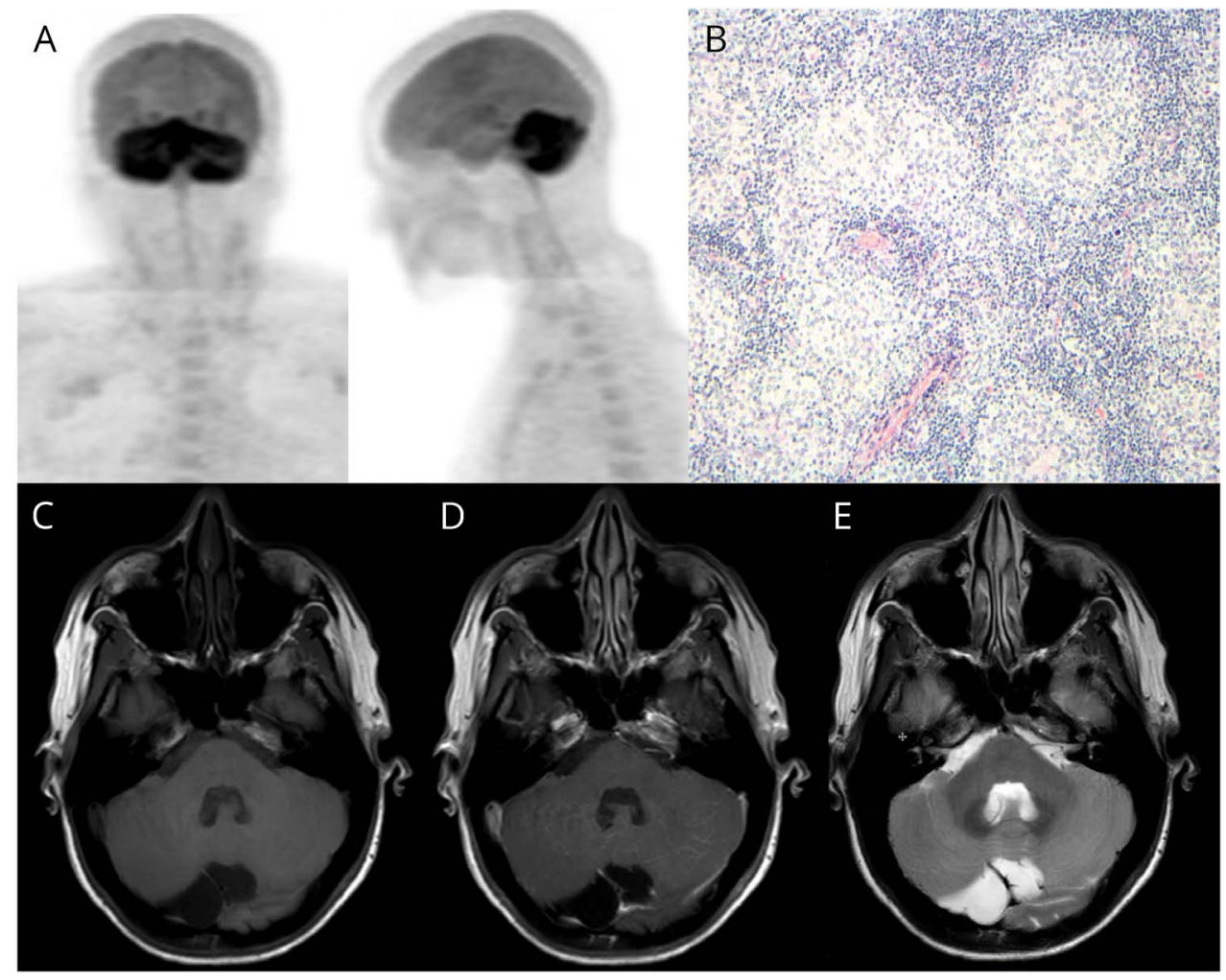

(A) FDG PET CT coronal and sagittal images, showing diffusely increased FDG uptake in the bilateral cerebellar hemispheres. Increased FDG uptake was also seen in the right axillary and mesenteric lymph nodes. (B) H\&E stain of the right axillary lymph node biopsy with histology finding of noncaseating granuloma. Stains for microorganism were negative (Warthin-Starry, Gomori methenamine silver, acid-fast bacillus). (C-E) Brain MRI performed 2 days before FDG PET. (C) Axial T1 precontrast sequence with mild generalized volume loss and mega cisterna magna. (D) Axial T1 postcontrast sequence with no abnormal enhancement. (E) Axial T2 sequence with no signal abnormalities. FDG PET = fluorodeoxyglucose positron emission tomography; $\mathrm{H \& E}=$ hematoxylin and eosin.

underwent excisional biopsy of a right axillary lymph node, which on histopathology demonstrated numerous well-formed, nonnecrotizing granulomata. Gomori methenamine silver and acid-fast stains were negative for fungi and acid-fast bacteria, respectively. Flow cytometry performed on peripheral blood, CSF, and the right axillary lymph node did not identify any abnormal B- or T-cell populations. She was diagnosed as probable neurosarcoidosis, with biopsy that confirmed systemic sarcoidosis in the context of a consistent clinical neurologic syndrome. A brain biopsy was considered but deferred given the risk. Her fevers and neurologic symptoms promptly improved after initiation of an empiric three-day course of IV methylprednisolone $1000 \mathrm{mg}$ daily, followed by a slow oral prednisone taper. She was placed on mycophenolate mofetil for maintenance therapy. At 1 month after discharge, her neurologic symptoms had completely resolved, and she returned to work. At 6 months clinic follow-up, she had no residual symptoms or neurologic signs and had no recurrent episodes. At 22 months electronic and phone follow-up, she continued to report stability without residual symptoms. Repeat FDG-PET scan was considered to determine change in hypermetabolic activity after treatment, but could not be obtained because of cost barriers.

\section{Discussion}

We present a unique case of probable neurosarcoidosis with a clinical presentation and a pattern of diffuse cerebellar involvement that has not been previously reported in the literature to our knowledge. ${ }^{1,5,6}$ Extensive diagnostic workup with MRI, CSF analysis, and serologic studies was unrevealing, and the diagnosis was uncertain until FDG-PET discovered cerebellar pathology and additional lymphadenopathy, eventually allowing confirmation of systemic sarcoidosis. FDG-PET is often used in the workup of malignancy, and more recently, it has become increasingly established to identify hypermetabolic extrapulmonary sites of sarcoidosis. ${ }^{3,7}$ However, FDG-PET findings of CNS activity are not well established to diagnose neurosarcoidosis. Our case demonstrates that FDG-PET may show abnormal metabolic activity in the brain even when conventional MRI imaging is unrevealing. Such discrepancy between MRI and FDG-PET findings has been previously reported in 2 cases of spinal sarcoidosis. $^{4,5}$ In addition, FDG-PET may identify lesions amenable to biopsy even when conventional imaging techniques do not. In summary, FDG-PET may have a critical role in contributing to the diagnosis of neurosarcoidosis, especially when serologic studies and conventional imaging remain nondiagnostic.

\section{Author contributions}

Y. Wang: major role in the acquisition of data, analysis of the data, and drafting the manuscript for intellectual content. $\mathrm{J}$. Andrews: analysis of the data and revising the manuscript for intellectual content. P. Jenkins Colon: major role in the 
acquisition of data and revising the manuscript for intellectual content. A. Wundes: major role in the acquisition of data, analysis of the data, and revising the manuscript for intellectual content.

\section{Study funding}

No targeted funding.

\section{Disclosure}

Y. Wang reports no disclosures; J. Andrews served on the editorial board for Arthritis Care and Research, received research support from NIH/NIA, NIH/NIAMS; P. Jenkins Colon reports no disclosures; A. Wundes received speaker honoraria from Multiple Sclerosis Association of America, received research support from Biogen, Alkermes, NMSS. Full disclosure form information provided by the authors is available with the full text of this article at Neurology. org/NN.

Received June 4, 2018. Accepted in final form August 15, 2018.

\section{References}

1. Nowak DA, Widenka DC. Neurosarcoidosis: a review of its intracranial presentation. J Neurol 2011;248:363-372.

2. Dubey N, Miletich RS, Wasay M, Mechtler LL, Bakshi R. Role of fluorodeoxyglucose positron emission tomography in the diagnosis of neurosarcoidosis. J Neurol Sci 2002;205:77-81.

3. Sobic-Saranovic D, Artiko V, Obradovic V. FDG PET imaging in sarcoidosis. Semin Nucl Med 2013;43:404-411.

4. Huang JF, Aksamit AJ, Staff NP. MRI and PET imaging discordance in neurosarcoidosis. Neurology 2012;79:1070.

5. Bartels S, Kyavar L, Blumstein N, et al. FDG PET findings leading to diagnosis of neurosarcoidosis. Clin Neurol Neurosurg 2013;115:85-88.

6. Fuller GN, Guiloff RJ. Clinical reports: cerebellar syndrome in sarcoidosis. Postgrad Med J 1987;63:1083-1084.

7. Pekarski E, Benali K, Rouzet F. Nuclear imaging in sarcoidosis. Semin Nucl Med 2018;48:246-260. 


\section{Neurology $^{\odot}$ \\ Neuroimmunology \& Neuroinflammation}

\section{FDG-PET abnormalities leading to the diagnosis of an unusual case of probable neurosarcoidosis}

Yujie Wang, James Andrews, Paula Jenkins Colon, et al.

Neurol Neuroimmunol Neuroinflamm 2018;5;

DOI 10.1212/NXI.0000000000000506

This information is current as of September 26, 2018

\section{Updated Information \& \\ Services}

References

Subspecialty Collections

Permissions \& Licensing

Reprints including high resolution figures, can be found at:

http://nn.neurology.org/content/5/6/e506.full.html

This article cites 7 articles, 1 of which you can access for free at: http://nn.neurology.org/content/5/6/e506.full.html\#\#ref-list-1

This article, along with others on similar topics, appears in the following collection(s):

Autoimmune diseases

http://nn.neurology.org//cgi/collection/autoimmune_diseases

PET

http://nn.neurology.org//cgi/collection/pet

Information about reproducing this article in parts (figures,tables) or in its entirety can be found online at:

http://nn.neurology.org/misc/about.xhtml\#permissions

Information about ordering reprints can be found online:

http://nn.neurology.org/misc/addir.xhtml\#reprintsus

Neurol Neuroimmunol Neuroinflamm is an official journal of the American Academy of Neurology.

Published since April 2014, it is an open-access, online-only, continuous publication journal. Copyright

Copyright $\odot 2018$ The Author(s). Published by Wolters Kluwer Health, Inc. on behalf of the American

Academy of Neurology.. All rights reserved. Online ISSN: 2332-7812.

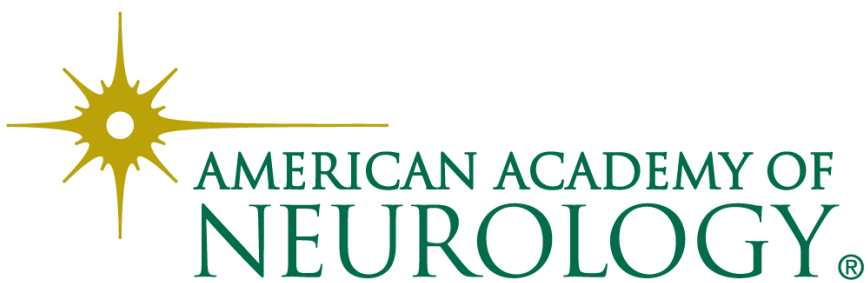

